DOE/ER $14077-F$

DE/ER/14077 - T/

\title{
PARALLEL NANOMETER SCALE FABRICATION
}

Final Report

for Project Period September 19, 1989 - September 14, 1992;

Continuation period September 15, 1992 - September 14, 1993

Kenneth Douglas

University of Colorado

Boulder, Colorado 80309

September 1993

Prepared for

THE U.S. DEPARTMENT OF ENERGY

AGREEMENT NO. DE-FG02-89ER14077 


\begin{abstract}
A B S T R A C T
Our approach to nanotechnology stresses parallel (as opposed to serial) processing and self-assembly techniques and we have demonstrated a basic parallel nanofabrication process that will enable a wide variety of nanometer-scale structures to be made. The process of nanometer molecular lithography employs two-dimensional biomolecular crystals as patterning elements in the parallel fabrication of structures on the 1-10 nm length scale. We have further demonstrated the fabrication of composite biomolecular/solid state heterostructures of nanometer dimension (nanoheterostructures). We are presently pursuing central issues in the development of nanotechnology such as the understanding and control of fluctuations and structural variations as well as applications of our nanofabrication process. An example of the latter is the formation of porous silicon having monodisperse arrays of silicon 'quantum wires' to elucidate the role of quantum confinement in the phenomenon of luminescent silicon.
\end{abstract}




\section{DISCLAIMER}

Portions of this document may be illegible in electronic image products. Images are produced from the best available original document. 


\title{
NOTICE
}

This report was prepared as an account of work sponsored by the United States Government. Neither the United States nor the Department of Energy, nor any of their employees, nor any of their contractors, subcontractors, or their employees, makes any warranty, express or implied, or assumes any legal liability or responsibility for the accuracy, completeness, or usefulness of any information, apparatus, product or process disclosed or represents that its use would not infringe privately-owned rights.

\section{COPYRIGHT NOTICE}

By acceptance of this article, the publisher and/or recipient acknowledges the United States Government's right to retain a nonexclusive, royalty-free license in and to any copyright covering this paper.

\section{DISCLAIMER}

\begin{abstract}
This report was prepared as an account of work sponsored by an agency of the United States Government. Neither the United States Government nor any agency thereof, nor any of their employees, makes any warranty, express or implied, or assumes any legal liability or responsibility for the accuracy, completeness, or usefulness of any information, apparatus, product, or process disclosed, or represents that its use would not infringe privately owned rights. Reference herein to any specific commercial product, process, or service by trade name, trademark, manufacturer, or otherwise does not necessarily constitute or imply its endorsement, recommendation, or favoring by the United States Government or any agency thereof. The views and opinions of authors expressed herein do not necessarily state or reflect those of the United States Government or any agency thereof.
\end{abstract}


In the report that follows we will evaluate progress in our research activities under the three headings: Pattern Transfer to Smooth Substrates, Pattern Development, and Mask Removal.

\section{PATTERN TRANSFER TO SMOOTH SUBSTRATES}

\section{First Demonstration}

We have recently demonstrated that a nanostructured metal oxide screen fabricated as shown in Figure 1 can act as a mask for the pattern transfer of a periodic array of holes to the underlying substrate [2]. In this study the stoichiometry of the metal oxide was determined by spectroscopic ellipsometry to be $\mathrm{TiO}_{1.9}$ and for the ensuing discussion we will denote the titanium oxide film as $\mathrm{TiO}_{\mathrm{x}}$. The AFM image before FAB milling in Figure 1a shows that, as deposited, the $\mathrm{TiO}_{\mathrm{X}}$ thin film is flat and of uniform thickness off-S-layer and exhibits a periodic thickness variation and surface height modulation on-S-layer. The AFM surface contour plot of Figure $1 \mathrm{~b}$, taken on the line indicated in Figure 1a, shows the on-S-layer modulation amplitude is $\sim 3 \mathrm{~nm}$ and the peak on-S-layer height is $\sim 6 \mathrm{~nm}$ above the graphite plane. This is less than the thickness reported from freeze-dried samples and may be attributable to shrinkage owing to air-drying of the S-layer sheets used in these particular experiments [1]. The after-milling image, Figure $2 \mathrm{a}$, shows that the $\mathrm{TiO}_{\mathrm{X}}$ thin film on-Slayer is modified by the FAB milling, forming a mesh composed of periodic arrays of $10 \mathrm{~nm}$ holes. Off S-layer, random holes appear on the graphite substrate, likely the result of localized contamination on the otherwise atomically smooth graphite surface. The after-milling AFM image shows that the holes penetrate both the $\mathrm{TiO}_{\mathbf{x}}$ film and the graphite substrate, both on and off-S-layer. In fact, there is considerable erosion of the carbon layer. The AFM profile of Figure $2 b$, taken on the line in Figure 2a, shows that after FAB milling the protein layer is collapsed somewhat, possibly by shallow implantation of the Ar atoms, to a measured thickness of $\sim 4 \mathrm{~nm}$. The off-S-layer holes are as deep as $4.5 \mathrm{~nm}$ below the graphite surface. The on-S-layer holes, as measured from the graphite surface, are etched $\sim 1.5 \mathrm{~nm}$ into the carbon. The difference between the on-S-layer and off-S-layer hole depths, $\sim 3 \mathrm{~nm}$, may be attributed to the additional height of the protein structures which protrude into the pores on-S-layer [2]. This "hole punching" is not observed in milled, bare HOPG, although slight ( $2 \AA \mathrm{rms})$ surface roughening is found, similar to that observed by Eklund et al. [3].

The off-S-layer presence of the $\mathrm{TiO}_{\mathbf{x}}$ film after milling combined with the erosion of the graphite at the holes show that the $3.5 \mathrm{~nm}$ thick $\mathrm{TiO}_{\mathrm{X}}$ is effectively acting as a mask for the $\mathrm{FAB}$ milling of carbon. It appears that the process of hole formation in the $\mathrm{TiO}_{\mathbf{X}}$ film occurs by heterogeneous nucleation and growth, wherein holes open under FAB only at nucleation sites (perhaps thin spots in the $\mathrm{TiO}_{\mathrm{X}}$ ). On-S-layer this process is controlled, since the S-layer produces in the deposited $\mathrm{TiO}_{\mathrm{X}}$ a periodic array of nucleation sites leading to a periodic array of holes. Once a hole is formed, continued milling erodes the carbon and deposits it near the hole edge.

Evidence for this can be obtained by quantitative analysis of hole profiles. Structure of individual holes is more easily measured off-S-layer because each hole is isolated from the others. Hole profiles were directly measured by AFM. The inset of Figure 3 shows a scale profile of a $7.5 \mathrm{~nm}$ deep hole. Volumes were calculated by numerical integration from the AFM raw data files of off-Slayer holes. In Figure 3, RV, the annular ring volume (excess volume above the milled $\mathrm{TiO}_{\mathrm{X}}$ surface plane) is plotted against CV+TV, the total volume removed (volume missing below the $\mathrm{TiO}_{\mathrm{X}}$ surface 
plane) for a number of different hole sizes. The values for RV lie close to the CV+TV line, indicating that the excess volume of material deposited around the hole circumference is close to the total excess volume of material (both $\mathrm{TiO}_{\mathrm{X}}$ and $\mathrm{C}$ ) removed from the hole itself. The convolution of the finite tip radius on the AFM with a small hole profile could cause the measured hole depths to be anomolously low [4]. Then, for smaller holes, RV would be larger than CV+TV, an effect which is, in fact, not seen in Figure 3.

(a)

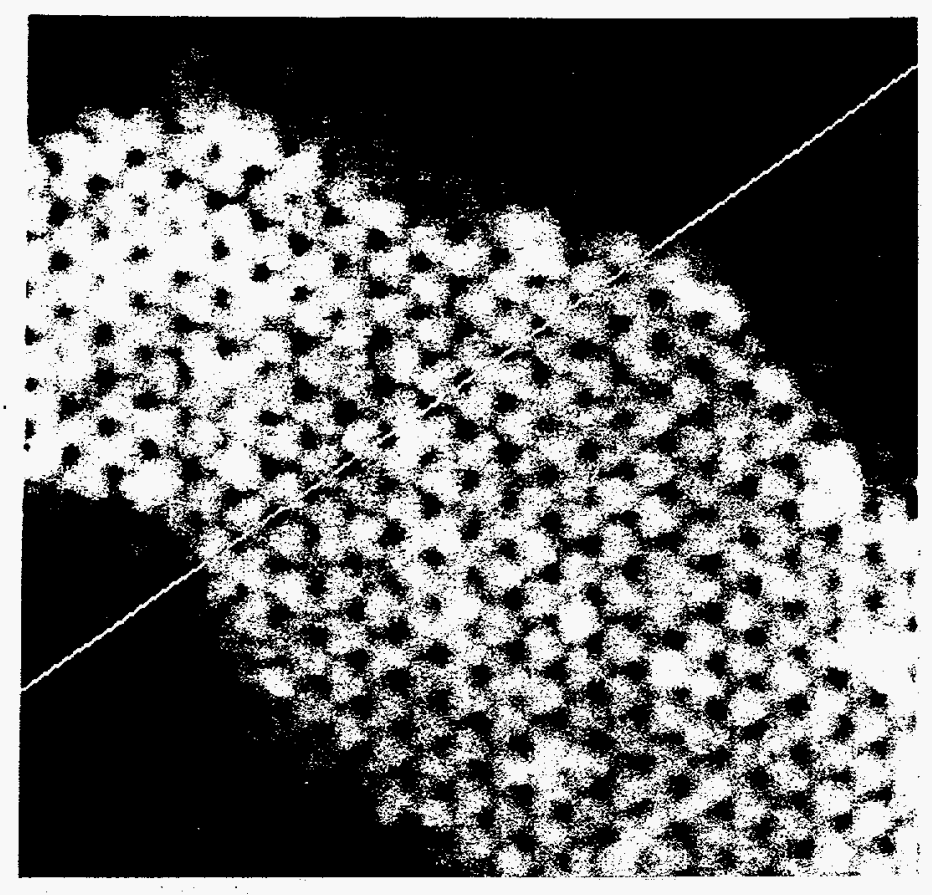

(b)

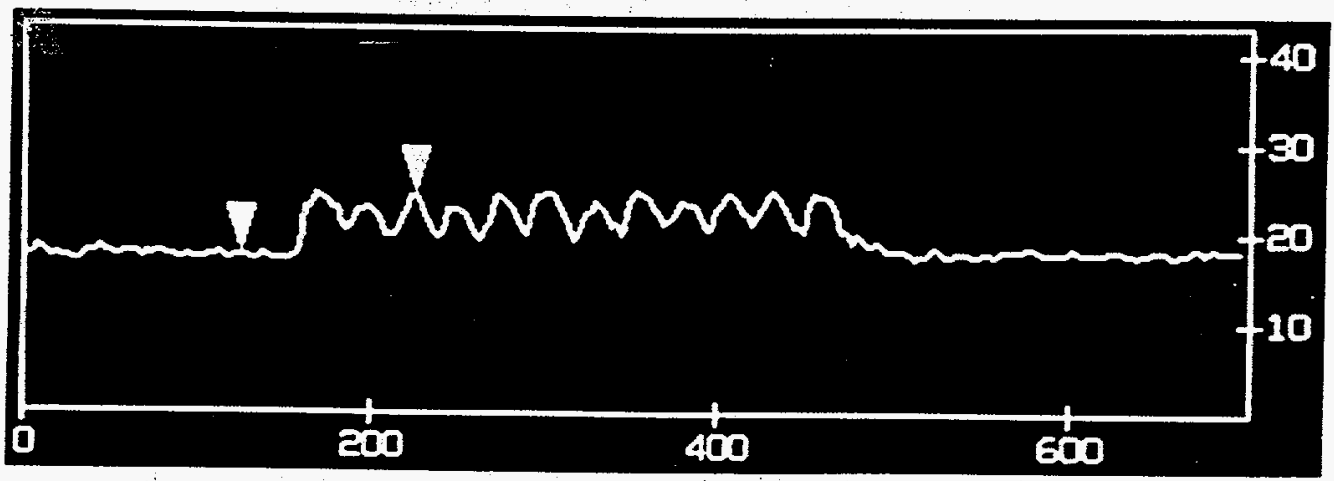

Figure 1: (a) Image of $\mathrm{TiO}_{\mathrm{x}}$ coated on-S-layer and off-S-layer areas before $\mathrm{FAB}$ milling. The image shows both the two dimensional hexagonal lattice on-S-layer as well as smooth off-S-layer areas. The lattice parameter of $22 \mathrm{~nm}$ serves to indicate the scale length; (b) AFM crosssection profile of unmilled $\mathrm{TiO}_{\mathbf{x}}$ coated S-layer along the line in Figure 5(a). The vertical height difference between the arrowheads is $6.1 \mathrm{~nm}$ 


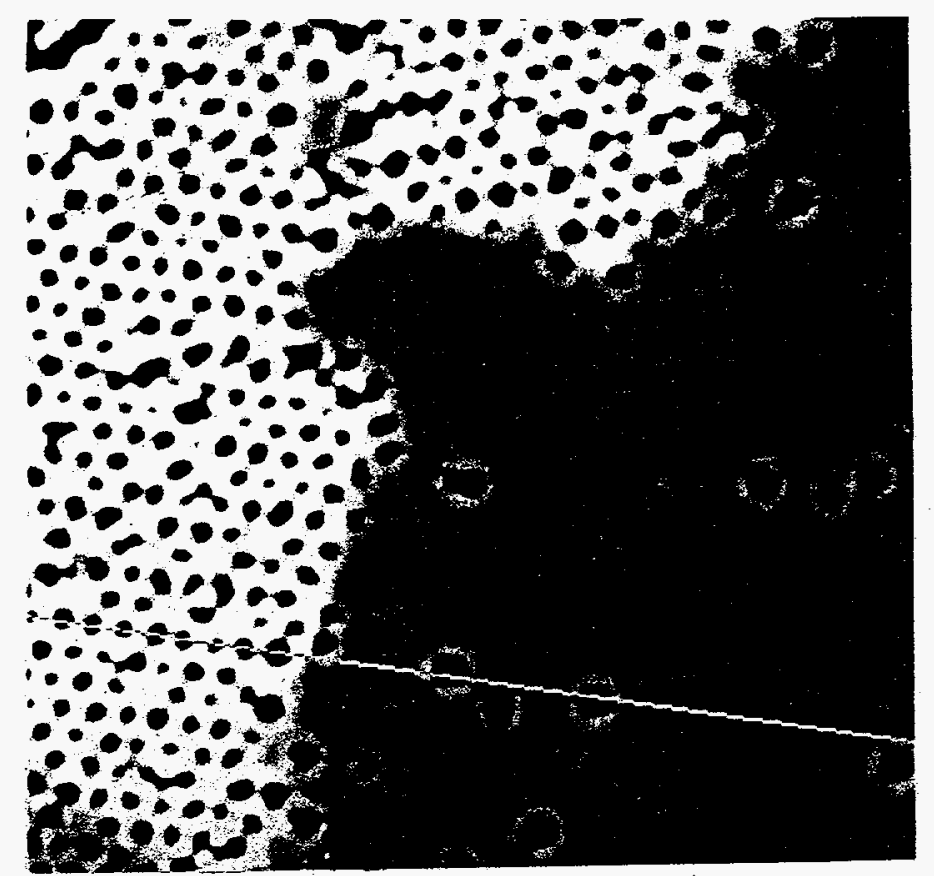

(a)

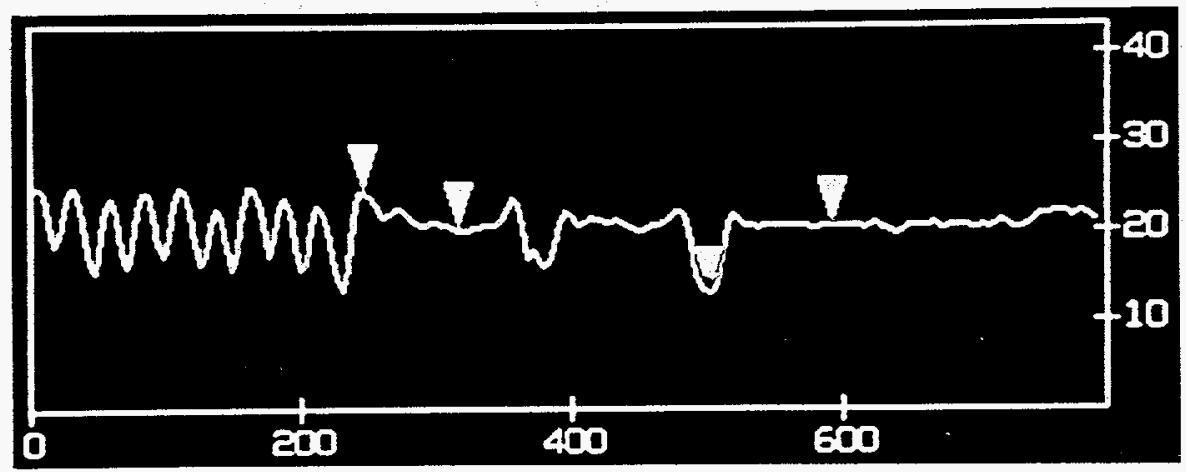

(b)

Figure 2: (a) Image of $\mathrm{TiO}_{\mathrm{x}}$ coated on-S-layer and off-S-layer areas after FAB milling; (b) AFM cross-section profile of milled $\mathrm{TiO}_{\mathrm{x}}$ coated S-layer along the line in Figure 6(a). The vertical distance between the leftmost set of arrowheads is $4 \mathrm{~nm}$ and the vertical distance between the rightmost set of arrowheads is $8 \mathrm{~nm}$. The erosion of deep holes in the carbon is evident, as are the annular rings of material at the hole edges. 


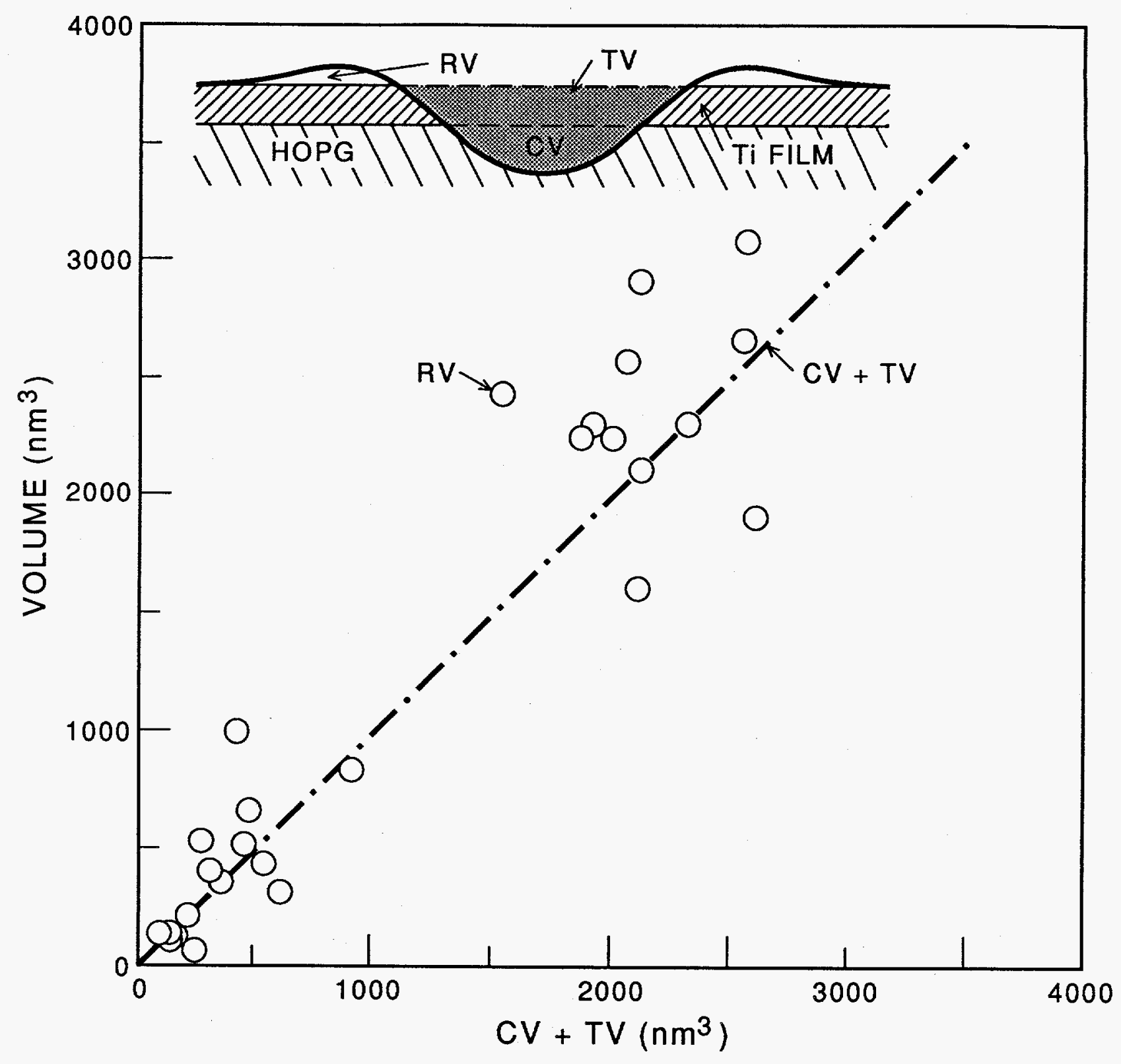

Figure 3: Annular ring volume, RV (o), and total removed volume, CV + TV (----), for holes of various sizes. The total removed volume, $C V+T V$, and annular ring volume, $R V$, are

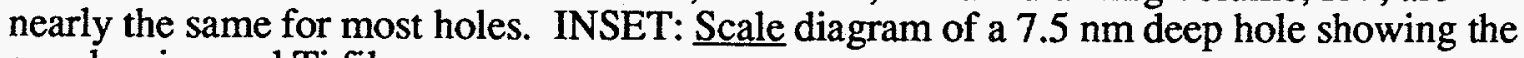
annular ring and Ti film. 
Thus we have shown that a $\mathrm{TiO}_{\mathrm{X}}$ film, although only $3.5 \mathrm{~nm}$ thick, can act, in the absence of random nucleation sites, as an effective mask material for FAB milling of HOPG.

\section{Crystalline Silicon}

Following the initial demonstration of pattern transfer to an HOPG substrate we are pursuing experiments to achieve pattern transfer to substrates of interest. One such material is silicon, owing, in part, to the great interest in the luminescent properties of porous silicon following the pioneering work of Canham in 1990 in which anodic etching of bulk silicon in hydrofluoric acid/ethanol solutions was shown to produce porous/luminescent silicon [5]. As of this writing there have been a plethora of experiments reported which have been interpreted to suggest quite different mechanisms to explain the observed phenomenon. Specifically, explanations include (i) quantum confinement in Si quantum wires, (ii) the formation of siloxene, (iii) chemisorbed molecules on the vast surface area provided by porous silicon, (iv) the formation of amorphous silicon, (v) some combination of the above. We are working toward the objective of using our metal oxide masks to define the initial positions of the etch sites on the silicon surface prior to the anodic etching of the silicon. The shallow etch pits in the silicon surface resulting from the FAB milling will be deepened either by anisotropic wet chemical etching or by dry etching via plasma or reactive ion etching. After deep initial pore locations are defined in the silicon surface, it is straightforward to remove the mask (protein crystal plus metal oxide) chemically using a titanium etchant (manuscript in preparation). Consequently, by periodic nanostructuring of the silicon surface prior to anodic etching, we will fabricate porous silicon with uniform pore diameters and uniform silicon 'column' diameters and thus produce a monodisperse array of silicon quantum wires. This will enable us to elucidate the role of quantum confinement in the phenomenon of luminescent silicon. Moreover, should quantum confinement be found to play a role in the observed luminescence, then the availability of crystalline, biomolecular patterning templates with a wide range of lattice constants may enable us to fabricate porous silicon with a spectrum of pore diameters and silicon 'column' diameters and thus to controllably tune the wavelength of the resulting luminescence. In addition, we note that the role of periodic nanostructuring on operative effects is unknown.

In our work to date on this project we have successfully addressed two major requirements for the patterning of macroscopic areas of silicon: (1) adhesion-monolayer coverage of the majority of the silicon substrate by the $\sim 1$ micron diameter protein crystals; and (2) sidedness-the cytoplasmic side (as opposed to the exoplasmic side) of the protein crystals must face up (that is, away from the substrate) in order to produce a satisfactory metal oxide mask and subsequent pattern transfer from the mask to the substrate. In fact, the solution to both these issues was neatly provided in one step by application of a suitably chosen silane coupling agent to the silicon surface prior to the deposition of the protein crystals. Glycidoxypropyltrimethoxysilane applied to the silicon surface provided excellent coverage over macroscopic areas. Figure 4 a shows representative coverage (the region shown is limited only by the maximum scan size of the AFM scan head), and Figure $4 \mathrm{~b}$ shows a higher magnification view of the metallized (but unmilled) patterning templates, that is, the metallized protein crystals. Moreover, the glycidoxypropyl silane coupler selectively binds to the carbohydrate moiety found only on the exoplasmic side of the protein crystals and thus ensures that the cytoplasmic side of the protein crystal is face up. Figure 5 shows a portion of a nanostructured titanium oxide mask formed on a (100) silicon substrate. The protruding hillocks are metal oxidecoated protein and the holes in the mask are hexagonally ordered with a lattice spacing of $20 \mathrm{~nm}$. 
The bottom most portion of the holes are etch pits which extend several nanometers into the silicon substrate which is directly beneath the metal oxide mask.

(a)

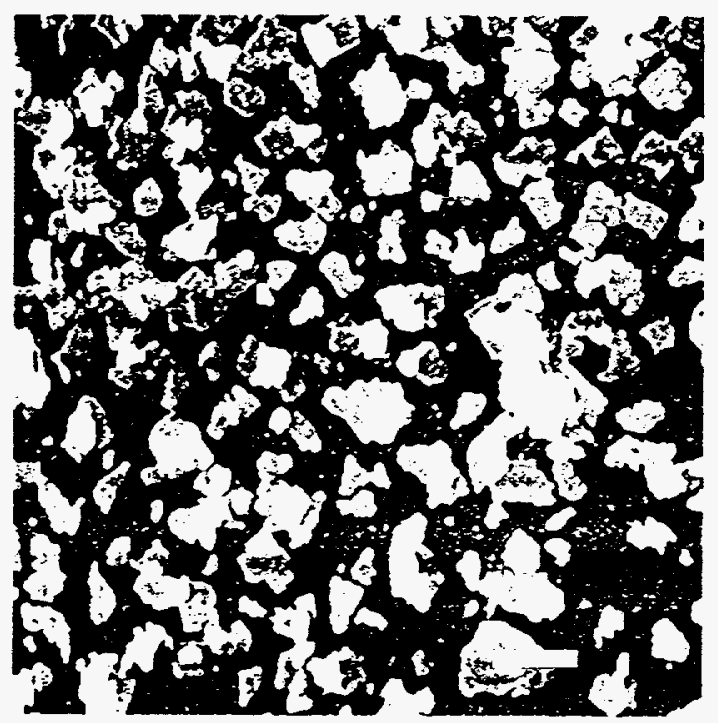

(b)

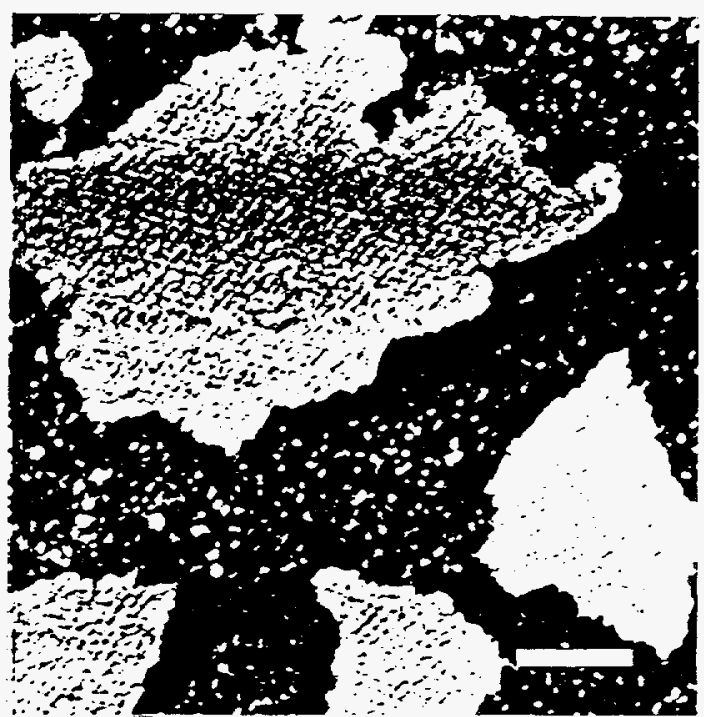

Figure 4: (a) Low magnification view of metallized (but unmilled) S-layer on a silanized Si substrate (scale bar $=1 \mu \mathrm{m})$; (b) Higher magnification view of (a) (scale bar $=250 \mathrm{~nm})$.

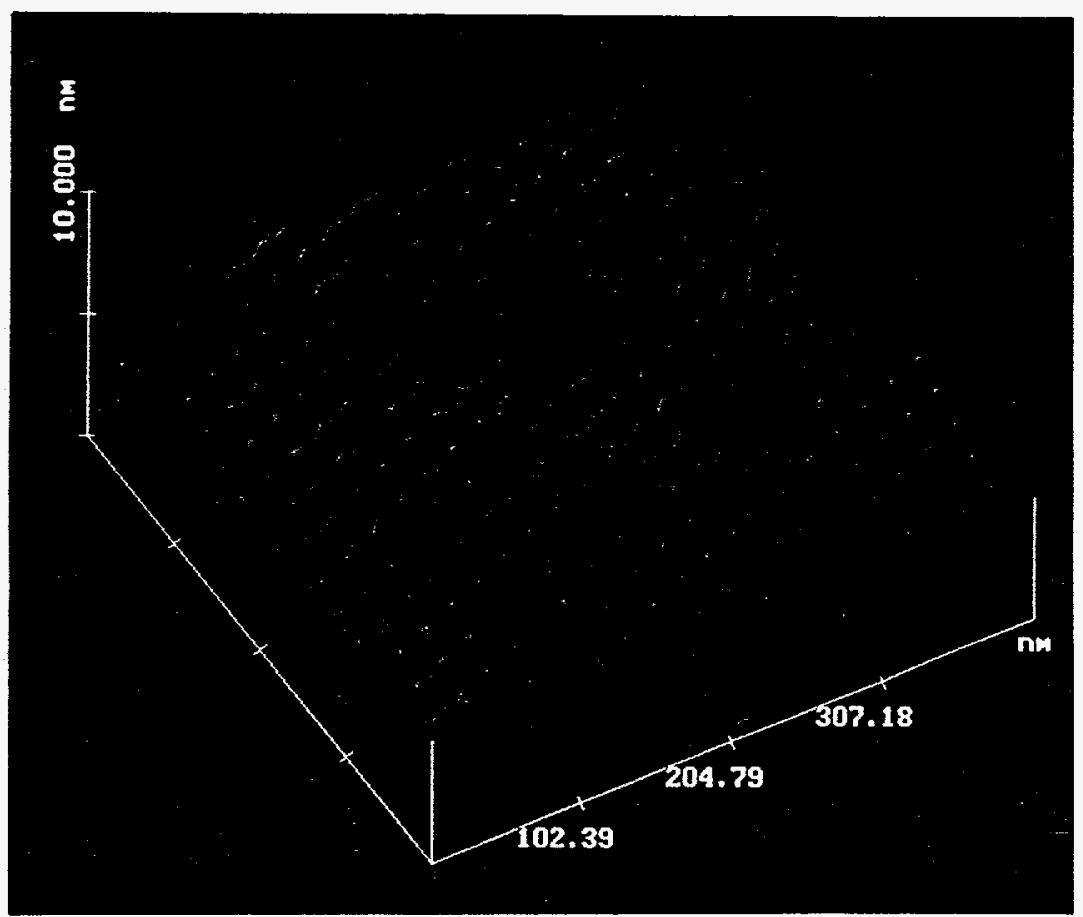

Figure 5: AFM surface mode image, fourier filtered, of a portion of a nanostructured titanium oxide mask on a (100) silicon substrate. 
In addition to our work in progress on silicon substrates we are also engaged in experiments to transfer a nanostructured pattern to metal substrates. One reason for our interest is the compelling technological goal to develop a process for fabricating large arrays of interconnected nanometerscale metal tunnel junctions for coulomb blockade or "single-electronics" applications. In very small normal metal tunnel junctions the change in potential due to a single electron on an electrode can cause a significant reduction in the tunneling rate. This phenomenon, also known as the coulomb blockade, provides the physical basis for a new class of electronic devices [6]. Although current devices at the $100 \mathrm{~nm}$ scale only operate well at low temperatures, when coulomb blockade devices are implemented at the molecular scale the coulomb energy associated with a single electron will become large, and operation in liquid nitrogen or even at room temperature is expected. To date we have succeeded in forming $\mathrm{TiO}_{\mathrm{X}}$ masks and, concomitantly, nanostructured periodic arrays of etch pits on the surfaces of both noble metal $(\mathrm{Pt})$ and metal oxide ( $\left.\mathrm{Ta}_{2} \mathrm{O}_{5}\right)$ substrates. These results are analogous to those we have obtained with crystalline Si substrates. We are now exploring methods such as plasma etching and reactive ion etching to impress these patterns more deeply (several tens of nanometers) into the substrate. After doing this we will remove the mask (S-layer plus $\mathrm{TiO}_{\mathrm{x}}$ ) and use electron beam lithography to attach leads to nanostructured portions of the metal and perform a variety of electron transport measurements (e.g., measurement of the electron diffusion constant) in order to electronically characterize these parallel fabricated metal nanostructures.

\section{PATTERN DEVELOPMENT}

\section{Microstructural Characteristics of Ultrathin Metal Films}

We have used transmission electron microscopy (TEM) to evaluate the microstructural modification of a variety of ultrathin films (transition and noble metals) undergoing parallel molecular lithography [7]. Thin films of Ti, Ta, Pt, $\mathrm{Pt} / \mathrm{C}, \mathrm{Pt} / \mathrm{Ir}, \mathrm{Pt} / \mathrm{Ir} / \mathrm{C}, \mathrm{Va}, \mathrm{Cr}, \mathrm{Ni}, \mathrm{Ag}, \mathrm{Zr}$, and $\mathrm{Nb}$ show dramatic differences in their response to this method of nanotexturing. It was found that metals which deposited as amorphous or very fine grained layers and did not crystallize or grain coarsen during milling were the most likely to form uniform nanostructures. These included $\mathrm{Ti}, \mathrm{Ta}, \mathrm{Nb}, \mathrm{Zr}$ and $\mathrm{Cr}$.

An example of the disparity in the pattern creation in ultrathin films of different materials is presented in bright field electron micrographs in Figure 6. The dark field electron micrograph of the nickel oxide film shows that grain coarsening has occurred after milling and the electron beam diffraction pattern corroborates this showing sharper more well defined rings [12]. By contrast, the titanium dark field image shows no grain structure and the diffraction pattern is composed of diffuse, broad halos, the signature of a very fine grained (or amorphous) structure.

We note that the pattern formation shown in Figure 6 is not optimal because the S-layer templates were air-dried onto the substrates prior to metallization rather than dried in such a way as to limit plastic deformation, for example, by using critical point drying 


\section{Defects in Naturally Occurring Protein Crystals}

We have studied fluctuation generation in the parallel nanofabrication process we have developed and have identified one source arising from fluctuations in the patterning template itself [8]. In the case of Sulfolobus acidocaldarius, for example, the symmetry of the S-layer arises from the hexagonal ordering of triads of dimers of S-layer protein (Figure 7). These proteins are held together by charge, not covalently. As the bacteria grows, additional S-layer protein is produced and added to the growing surface [9]. A sheet of protein having pure 6-fold symmetry cannot encase a volume [10]. Defect structures in S. acidocaldarius have been inferred from image analysis using high resolution TEM [11]. We have

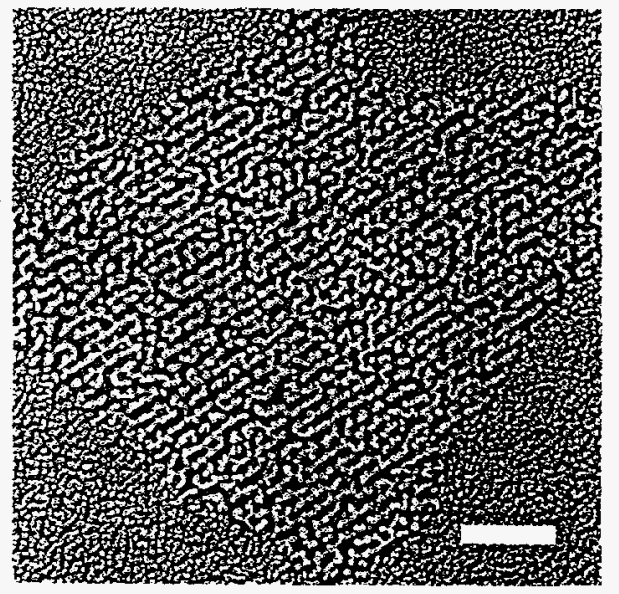

(a)

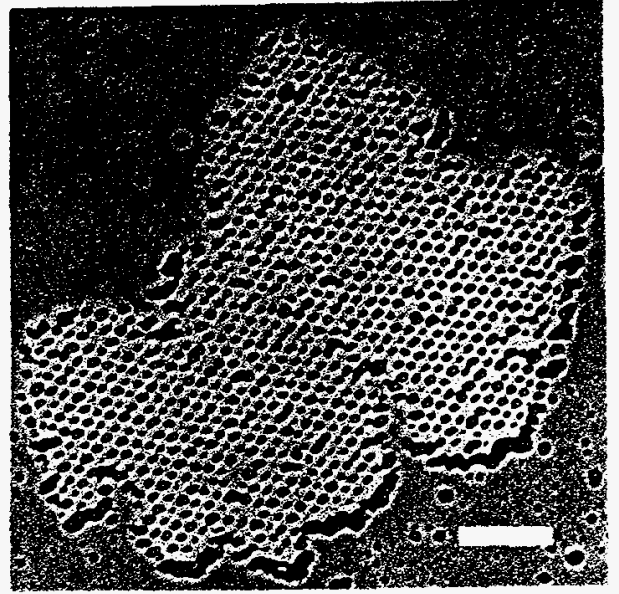

(b)

Figure 6: TEM micrographs of nanostructures formed from (a) nickel (oxide) (Scale bar $=140 \mathrm{~nm}$ ) and (b) titanium (oxide) (Scale bar $=150 \mathrm{~nm}$ ). In both cases, the S-layer of $S$. acidocaldarius was shadowed with $12 \AA$ of metal and fast atom beam (FAB) milled for 20 seconds. 


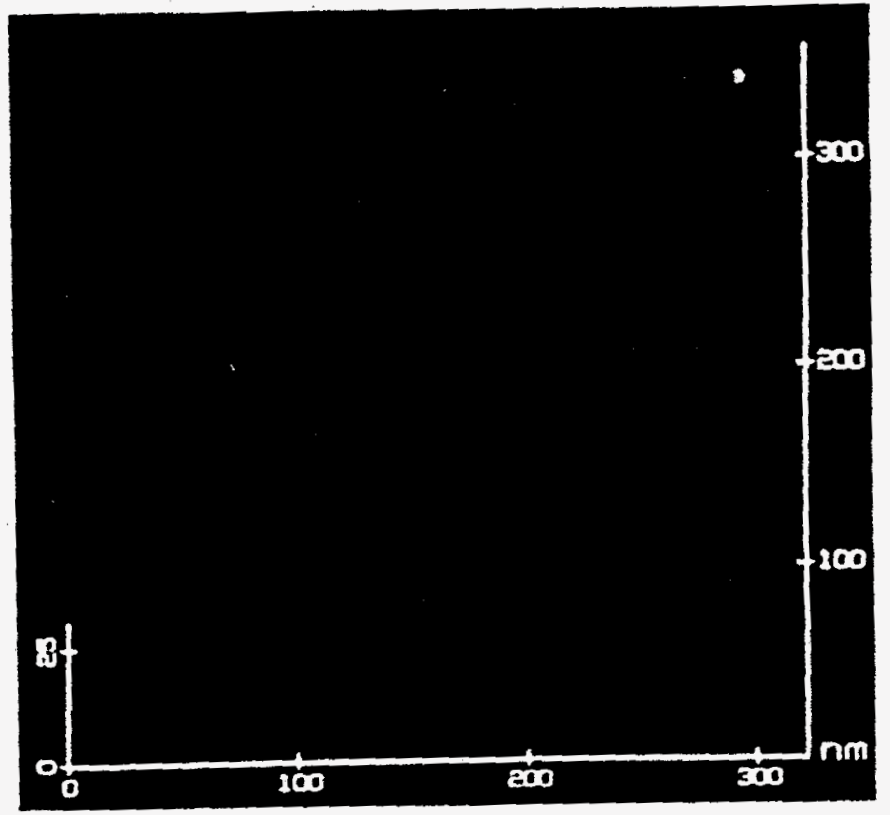

Figure 7: Atomic force microscope (AFM) image of cytoplasmic surface of S-layer of Sulfolobus acidocaldarius with has been air-dried and metallized. The triads (of dimers) of S-layer protein are clearly visible.

ourselves directly imaged twin boundaries in metallized S-layers from Sulfolobus acidocaldarius using atomic force microscopy (AFM) (Figure 8).

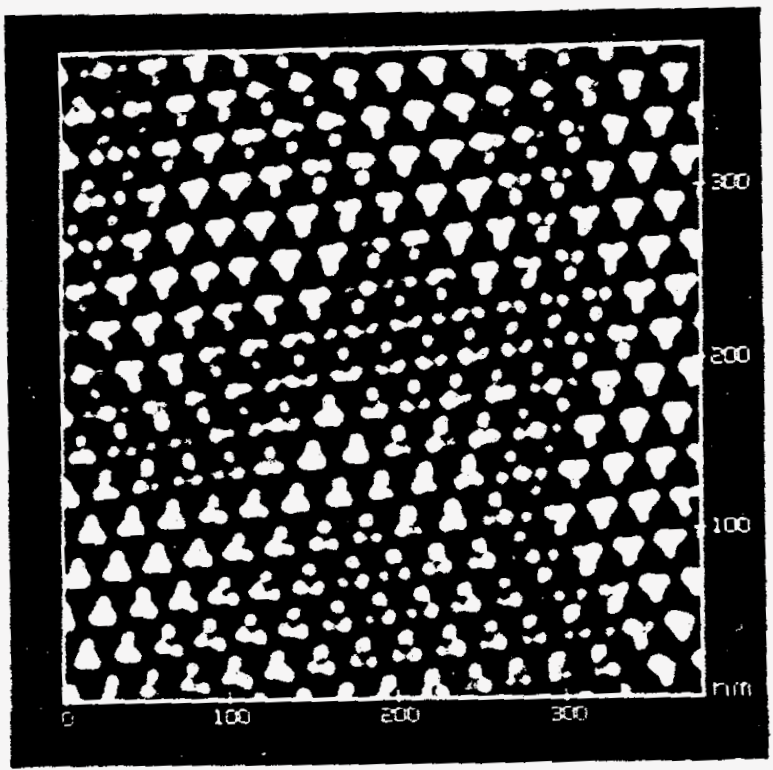

Figure 8: Atomic force microscope (AFM) image of cytoplasmic surface of S-layer of Sulfolobus acidocaldarius (air-dried and metallized) showing rotation twin boundary. The orientation of the triads of dimers changes at a twin boundary as shown. This image has been filtered using a Fast Fourier Transform to display more clearly the boundary. 


\section{MASK REMOVAL}

We have succeeded in removing the masking material (S-layer plus TiOx) and in thus exposing the 'bare' nanostructured substrate (manuscript in preparation). This has been accomplished by treating the masked, nanostructured surface with a metal oxide etchant which removes both the metal oxide overlayer and the protein crystal to which it is adhered. We have used two different commercial etchants supplied by Transene Company, Inc. One of the etchants, type TFT, is a hydrofluoric acid based etch and the other, TFTN type, is a hydrochloric acid based etch. Samples are treated with the etchant for $\sim 10^{\prime}$ at $80 \mathrm{C}$ and are then rinsed with distilled water and air dried. Analysis with X-ray photoelectron spectroscopy (XPS) confirmed preliminary results obtained with scanning tunneling microscopy (STM) and showed that the masking material was successfully removed.

\section{REFERENCES}

1. R. Prüschenk, W. Baumeister, European Journal of Cell Biology 45,185 (1987).

2. K.A. Taylor, J.F. Deatherage and L.A. Amos, Nature 299, 840 (1982).

3. E.A. Eklund, R. Bruinsma, J. Rudnick, R. Stanley Williams, Phys. Rev. Lett. 67, 1759 (1991).

4. M. Stedman, J. Microscopy 152, 611 (1988).

5. L.T. Canham, Appl. Phys. Lett. 57, 1046 (1990))

6. K.K. Likharev, IBM J. Res. Dev. 32, 144 (1988); D.V. Averin and K.K. Likharev in Mesoscopic Phenomena in Solids, B.L. Altshuler, P.A. Lee, and R.A. Webb, Eds. (Elsevier 1991).

7. G. Devaud and K. Douglas, "Microstructural Modification by Fast Atom Beam Milling of Nanotextured Ultrathin Metal Films," submitted to J. Vac. Sci. Technol. B.

8. G. Devaud, P. Furcinitti, J.C. Fleming, M.K. Lyon, and K. Douglas, Biophysical Journal 63, 630 (1992).

9. J. Smit, "Protein Surface Layers of Bacteria," in Bacterial Outer Membranes as Model Systems, M. Inouye, Ed. Wiley-Interscience, NY, 343 (1987).

10. D.C.D. Caspar and A. Klug, Cold Spring Harbor Symposium on Quantitative Biology 27, 1 24 (1962).

11. G. Lembcke, R. Durr, R. Hegerl, J. Microscopy 161(2), 263 (1991). 


\section{PUBLICATIONS}

"Microstructural Modification by Fast Atom Beam Milling of Nanotextured Ultrathin Metal Films," G. Devaud and K. Douglas, J. Vac. Sci. Technol. B 11(1), 32 (1993).

"Transfer of Biologically Derived Nanometer-Scale Patterns to Smooth Substrates," K. Douglas, G. Devaud, and N. A. Clark, Science 257, 642 (1992).

"Direct Observation of Defect Structure in Protein Crystals by Atomic Force Microscopy," G. Devaud, P. Furcinitti, J.C. Fleming, M.K. Lyon, and K. Douglas, Biophysical Journal 63, 630 (1992).

"Nanostructure Fabrication Using Biomolecular Templates," K. Douglas, J. Devaud, M.K. Lyon, and N.A. Clark, Proceedings of the International Symposium on the Physics and Chemistry of Finite Systems: From Clusters to Crystals, P. Jena, S.N. Khanna, and B.K. Rao (editors), Kluwer Academic Publishers, Dordrecht (1992).

"Nanometer Lithography by Fast Atom or Ion Beam Milling," G. Devaud, J. Fleming, K. Douglas, Mat. Res. Soc. Symp. Proc. 236,171 (1992).

"Biomolecular/Solid State Nanoheterostructures," K. Douglas, N.A. Clark, and K.J. Rothschild, Appl. Phys. Lett. 56, 692 (1990).

"Composite Biomolecular/Solid State Nanostructures," K. Douglas, N.A. Clark, and K.J. Rothschild, Mat. Res. Soc. Symp. Proc. 174, 151 (1990)

"Biologically Derived Nanometer-Scale Patterning on Chemically Modified Silicon Surfaces," B.W. Holland and K. Douglas (manuscript in preparation).

"Removal of Protein Crystal/Metal Oxide Masks from Nanometer-Scale Patterned Substrates ; STM and XPS Assay," B.W. Holland, J.T. Moore, and K. Douglas (manuscript in preparation).

"Silicon Quantum Dot Laser," J.I. Pankove, G. Moddel, and K. Douglas (invention disclosure filed, patentability review in progress).

In addition, during this funding period our work has been featured in the following publications:

"Biomolecular Materials," in Physics News, American Institute of Physics, pp. 22-23 (1992).

"Molecular Doily," in Popular Science, p. 16, December (1992).

"Protein Masks for Etching Tiny Holes," in Science News, p. 71, August (1992).

"Bacteria Pelts Could Start Nano-Fashion," in R\&D Magazine, p. 86, July (1992).

"Biomaterials and Nanotechnology," in The World and I, pp. 296-297, March (1991).

"Face to Face With Proteins," in Nature, 344, p. 591, April (1990).

"Bacteria, Templates and Gold Islands," in Science News, p. 191, March (1990). 